\title{
Reciprocal Inhibitory Glomerular Circuits Contribute to Excitation-Inhibition Balance in the Mouse Olfactory Bulb
}

\author{
Zuoyi Shao, ${ }^{D}$ Shaolin Liu, Fuwen Zhou, Adam C. Puche, and Michael T. Shipley
}

https://doi.org/10.1523/ENEURO.0048-19.2019

Department of Anatomy and Neurobiology, Program in Neurosciences, University of Maryland School of Medicine, Baltimore, Maryland 21201

\begin{abstract}
The major inhibitory interneurons in olfactory bulb (OB) glomeruli are periglomerular cells (PGCs) and short axon cells (SACs). PGCs and SACs provide feedforward inhibition to all classes of projection neurons, but inhibition between PGCs and SACs is not well understood. We crossed Cre and GFP transgenic mice and used virally-delivered optogenetic constructs to selectively activate either SACs or GAD65cre-ChR2-positive PGCs while recording from identified GAD65cre-ChR2-positive PGCs or SACs, respectively, to investigate inhibitory interactions between these two interneuron types. We show that GAD65cre-ChR2-positive PGCs robustly inhibit SACs and SACs strongly inhibit PGCs. SACs form the interglomerular circuit, which inhibits PGCs in distant glomeruli. Activation of GAD65cre-ChR2positive PGCs monosynaptically inhibit mitral cells (MCs), which complements recent findings that SACs directly inhibit MCs. Thus, both classes of glomerular inhibitory neurons inhibit each other, as well as OB output neurons. We further show that olfactory nerve input to one glomerulus engages the interglomerular circuit and inhibits PGCs in distant glomeruli. Sensory activation of the interglomerular circuit directly inhibits output neurons in other glomeruli and by inhibiting intraglomerular PGCs, may potentially disinhibit output neurons in other glomeruli. The nature and context of odorant stimuli may determine whether inhibition or excitation prevails so that odors are represented in part by patterns of active and inactive glomeruli.
\end{abstract}

Key words: circuit; dopamine; GABA; glomerular; inhibition; olfactory

\section{Significance Statement}

In the olfactory bulb (OB) odors are initially processed by glomeruli. Glomeruli are surrounded by a complex network of excitatory and inhibitory neurons that transform sensory inputs into neural signals transmitted to subsequent olfactory networks. Glomerular excitatory and inhibitory neurons are richly interconnected and provide feedforward excitation and feedback inhibition to glomerular output neurons. Our findings add to the capacity and complexity of glomerular networks by showing that interglomerular and intraglomerular inhibitory circuits are reciprocally interconnected. These circuits could modulate signals sent to higher brain regions by directly inhibiting output neurons or by disinhibiting them when inhibitory circuits inhibit each other.

\section{Introduction}

A fundamental principle in neuroscience is that the balance of excitation and inhibition determines neural circuit output signals. It is known that local circuit inhibi-

Received February 8, 2019; accepted May 20, 2019; First published May 30, 2019.

The authors declare no competing financial interests. tory neurons regulate excitatory output neurons but synapses between inhibitory neurons may disinhibit output neurons and play an important role in neural circuitry (Letzkus et al., 2015). 
Odorants are transduced by olfactory sensory neurons, whose axons form the olfactory nerve that synapses onto excitatory output neurons-mitral cells (MCs), tufted cells (TCs), and external tufted cells (ETCs) -in olfactory bulb (OB) glomeruli. These excitatory pathways are strongly modulated by inhibitory interneurons. There are nearly as many inhibitory neurons in the glomerular layer (GL) as in the granule cell layer (Parrish-Aungst et al., 2007). GL inhibitory neurons act on the apical dendrites, whereas granule cells inhibit the lateral dendrites of output neurons. In addition, some deep short axon cells send inhibitory projections to glomeruli (Eyre et al., 2008; Burton et al., 2017).

The principal glomerular inhibitory neurons are GABAergic periglomerular cells (PGCs), and GABAergic-DAergic short axon cells (SACs; Kosaka and Kosaka, 2008; Kiyokage et al., 2010). PGCs are primarily "uniglomerular", forming intraglomerular inhibitory circuits within a single glomerulus. In contrast, SACs are "multiglomerular", forming interglomerular circuitry, which inhibit neurons, in other glomeruli, including MCs/TCs (Aungst et al., 2003; Shirley et al., 2010; Liu et al., 2013, 2016).

Together, intraglomerular and interglomerular inhibitory circuits regulate neuronal spike output to downstream networks (Shao et al., 2012). Inhibitory synapses between PGCs and SACs could, thus, significantly impact odor output signals, but little is known about potential interactions between these two inhibitory interneuron types. Electron microscope studies show symmetric synapses between glomerular cells (Price and Powell, 1970; Pinching and Powell, 1971; Toida et al., 1994) and inhibitory interactions among unidentified glomerular neurons have been reported (Murphy et al., 2005). This suggests there may be inhibitory interactions between interglomerular and intraglomerular circuits but the cell-type identity (PGCs or SACs), extent of potential interactions and their impact on glomerular output neurons are not well understood. To investigate these questions, we crossed Cre and GFP transgenic mouse lines and virally delivered optogenetic constructs to selectively activate either SACs or PGCs while recording from GFP-expressing PGCs or SACs, respectively.

\section{Materials and Methods}

\section{Animals}

Mice used in this study include a transgenic expressing green fluorescent protein (GFP) under the control of the glutamic acid decarboxylase-65 promoter (GAD65gfp; courtesy of Dr. Gabor Szabo, Hungary) or under the con-

This work was supported by National Institutes of Health Grants DC010915 and DC005676.

S. Liu's present address: Howard University, Washington, DC 20059.

Z. Shao's present address: Mayo Clinic, Rochester, MN 55904.

Correspondence should be contacted at Michael $\mathrm{T}$ Shipley at mshipley@som.umaryland.edu.

https://doi.org/10.1523/ENEURO.0048-19.2019

Copyright (C) 2019 Shao et al.

This is an open-access article distributed under the terms of the Creative Commons Attribution 4.0 International license, which permits unrestricted use, distribution and reproduction in any medium provided that the original work is properly attributed. trol of the tyrosine hydroxylase promoter (THgfp; courtesy of Dr. Kazuto Kobayashi, Japan), and transgenic mice expressing Cre recombinase under the glutamic acid decarboxylase-65 promoter (GAD65cre; Jax mice strain, B6.129.GAD65cre) or under the control of the tyrosine hydroxylase promoter (THcre; Jax mice strain, B6.Cg$\mathrm{Tg}(\mathrm{Th}$-cre) $1 \mathrm{Tmd} / \mathrm{J})$. Double-heterozygous mice were generated by crossing a heterozygote THgfp with a heterozygote GAD65cre, or a heterozygote GAD65gfp with a heterozygote THcre. Colonies of transgenic mice were maintained by breeding wild-type C57BL/6J female mice with a heterozygous male THgfp, THcre, or GAD65cre, or a wild-type B6CBAF1/J with a heterozygous male GAD65gfp. Approximately equal numbers of male and female mice were used in the experiments (total 25 animals). Analysis of the responses in each experiment did not show evidence of sex differences, thus results from male and female animals were pooled in the reported $n$ for each experiment. All animal colonies and experimental procedures were performed in accordance with protocols approved by the Institutional Animal Care and Use Committee.

\section{Channelrhodopsin 2 expression}

The optogenetic construct channelrhodopsin 2 (ChR2) was expressed in GAD65cre/THgfp or THcre/GAD65gfp using a Cre-inducible adeno-associated virus serotype2.9 (AAV2.9) carrying a fusion construct of ChR2 to the mCherry fluorescent protein (AAV-hSyn-hChR2(H134R)mCherry; University of Pennsylvania Vector Core) injected into the GL of the medial side of each $O B$ between postnatal weeks 3 and 4 . Under deep anesthesia, the skull was exposed and a small hole $(0.5 \mathrm{~mm}$ diameter) drilled over each $\mathrm{OB}$ at coordinates at $3.95 \mathrm{~mm}$ from bregma and $0.2 \mathrm{~mm}$ from midline. Injections were performed using a pulled glass micropipette (tip size 10-15 $\mu \mathrm{m}$ ) and a pneumatic pressure injection apparatus (Picospritzer II, General Valve). AAV2.9 was injected into three points within the GL of the medial side of each bulb (depth: 2.0, 1.5, and $1.0 \mathrm{~mm}$ ) at a rate of $0.1 \mu \mathrm{l} / \mathrm{min}$ for $5 \mathrm{~min}$ with a total volume of $0.5 \mu \mathrm{l}$ per bulb. After 2-4 weeks for ChR2 mCherry fluorescent protein expression, acute horizontal OB slices were prepared for electrophysiology experiments.

\section{Slice preparation}

Animals were anesthetized with saturated vapor isoflurane and the OBs surgically removed. The bulbs were immediately secured to a cutting platform and immersed in $4^{\circ} \mathrm{C}$ oxygenated sucrose-artificial CSF (sucrose ACSF) containing the following (in mM): $26 \mathrm{NaHCO}_{3}, 1 \mathrm{NaH}_{2} \mathrm{PO}_{4}$, $3 \mathrm{KCl}, 5 \mathrm{MgSO}_{4}, 0.5 \mathrm{CaCl}_{2}, 10$ glucose, and 248 sucrose, equilibrated with $95 \% \mathrm{O}_{2}-5 \% \mathrm{CO}_{2}, \mathrm{pH}$ 7.38. Horizontal slices (400 $\mu \mathrm{m}$ thick) were cut with a Leica VT1200s vibratome. Slices were incubated in oxygenated ACSF (in mm): $124 \mathrm{NaCl}, 26 \mathrm{NaHCO}_{3}, 3 \mathrm{KCl}, 1.25 \mathrm{NaH}_{2} \mathrm{PO}_{4}, 2$ $\mathrm{MgSO}_{4}, 2 \mathrm{CaCl}_{2}$, and 10 glucose equilibrated with $95 \%$ $\mathrm{O}_{2}-5 \% \mathrm{CO}_{2}, \mathrm{pH} 7.38$ ) at $30^{\circ} \mathrm{C}$ for $20-30 \mathrm{~min}$ and then at room temperature $\left(22^{\circ} \mathrm{C}\right)$ in ACSF for at least $1 \mathrm{~h}$ before use. For recording, individual slices were transferred to a recording chamber and perfused with ACSF (as above) at a rate of $3 \mathrm{ml} / \mathrm{min}$ maintained at a temperature $30^{\circ} \mathrm{C}$ 
(Bipolar Temperature Controller). Target GFP-positive or MC cells were observed with a $40 \times$ water-immersion objective using an Olympus BX51W upright microscope equipped for near infrared differential interference contrast optics (Olympus Optical) and fluorescent excitation/ barrier filters suitable for visualization of mCherry/GFP.

\section{Electrophysiology}

Whole cell (current and voltage) patch-clamp recordings were performed using recording pipettes made from thick-wall borosilicate glass with filament (inner diameter: $0.75 \mathrm{~mm}$; Sutter Instruments) pulled on a P-97 FlamingBrown puller (Sutter). For current-clamp, the internal solution contained the following (in $\mathrm{mM}$ ): $120 \mathrm{~K}$-gluconate, $20 \mathrm{KCl}, 10 \mathrm{HEPES}, 2 \mathrm{MgCl}_{2}$, 2 Mg2ATP, $0.2 \mathrm{Na}$ 3GTP, 0.1 BAPTA, and $0.02 \%$ Lucifer yellow, pH 7.3 adjusted with $\mathrm{KOH}$ and for voltage-clamp contained the following (in mM): $120 \mathrm{CsMeSO}_{4}, 10$ QX-314, 10 HEPES, $1 \mathrm{MgCl}_{2}, 2.5$ $\mathrm{Mg}_{2}$ ATP, $0.2 \mathrm{Na}_{3} \mathrm{GTP}, 0.1$ BAPTA, 10 phosphocreatine, $\mathrm{pH} 7.3$ adjusted with $\mathrm{CsOH}$. Osmolarity for both solutions were in the range 287-295 mOsm. Recordings were discontinued if access resistance was $>20 \mathrm{M} \Omega$ at the beginning of whole-cell recording with typical access resistances of 10-20 M $\Omega$. Membrane capacitance $\left(C_{m}\right)$ for SACs was $6-10 \mathrm{pF}$ and for PGCs were 5-8 pF. All data were acquired with pCLAMP 9 software using a MultiClamp 700A amplifier, digitized with a Digidata 1322A A/D board (Molecular Devices), low-pass filtered online at 2 $\mathrm{kHz}$ (voltage-clamp, sampling rate of $5 \mathrm{kHz}$ ) or $10 \mathrm{kHz}$ (current-clamp, sampling rate of $40 \mathrm{kHz}$ ).

\section{Electrical and optical stimulation}

Electrical stimulation of olfactory nerve axons was delivered by bipolar glass electrodes made from theta borosilicate tubes (Sutter Instruments). The electrodes were visually positioned 3-4 glomeruli rostral to the recording site. Isolated constant current pulses $(100 \mu \mathrm{s}, 20-100 \mu \mathrm{A})$ were triggered by a PG4000A Digital Stimulator (Cygnus Technologies). Optical stimuli (0.5-12 mW) were delivered from a 25 $\mu \mathrm{m}$ multimode optical fiber ( 0.1 numerical aperture, $7^{\circ}$ beam spread; Thorlabs) coupled to a $150 \mathrm{~mW}, 473 \mathrm{~nm}$, diodepumped, solid-state laser (LWBL473083272) gated with a Uniblitz shutter (all light pulses were of $2 \mathrm{~ms}$ duration). Optical power delivered at the fiber tip was calibrated with a PM20A Power Meter (Thorlabs). The onset and duration of optical stimulation was measured during every experiment by splitting $1 \%$ of the laser beam out to a high speed ( $30 \mathrm{~ns}$ rise time) silicon photosensor (model 818-BB, Newport) and was recorded by the same MultiClamp 700A amplifier as the patch electrode.

\section{Data analysis}

Data were analyzed with Clampfit 9.2 (Molecular Devices). Statistical analysis and graphical presentation was performed with Origin (OriginLab). Statistical significance of population responses was calculated by using Student's $t$ test (comparing two groups) or ANOVA with Bonferroni post hoc (comparing $>2$ groups). Graphs and plotting were created with Origin 8.5 and CorelDraw 17 .

\section{Drugs and chemicals}

APV (50 M), NBQX (disodium salt, $10 \mu \mathrm{M}$ ), gabazine (GBZ; SR95531, $10 \mu \mathrm{M}$ ), 8-bromo-2,3,4,5-tetrahydro-3methyl-5- phenyl-1H-3-benzazepin-7-ol (SKF83566) hydrobromide $(10 \mu \mathrm{M}),(2 \mathrm{~S})-3-[[(1 \mathrm{~S})-1-(3,4-D i c h l o r o p h e n y l)$ ethyl]amino-2ydroxypropyl] (phenylmethyl) phosphinic acid hydrochloride (CGP55845, $10 \mu \mathrm{M}$ ), were purchased from Tocris Cookson. All other chemicals were purchased from Sigma-Aldrich. All drugs were bath applied by diluting in ACSF at the above-indicated doses unless otherwise stated. Drugs enter the recording chamber $45 \mathrm{~s}$ after switching fluid lines. To ensure adequate drug access to the slices, all recordings occurred no sooner than $5 \mathrm{~min}$ after fluid switch.

\section{Results}

The two major classes of glomerular inhibitory neurons are PGCs and SACs, which form intraglomerular and interglomerular circuits, respectively. The existence of spontaneous and evoked IPSCs in both cell types (Murphy et al., 2005; Liu et al., 2015; Brill et al., 2016) and electron microscopy evidence for synapses between glomerular inhibitory neurons (Price and Powell, 1970; Pinching and Powell, 1971; Toida et al., 1994) suggests that PGCs and SACs are synaptically interconnected, but it is not known whether both are involved. To explore this, and to see if intraglomerular and interglomerular circuits reciprocally inhibit each other, we used a genetic-ChR2 strategy to assess the actions of PGCs and SACs on one another.

\section{SACs directly inhibit PGCs}

Activation of the SAC interglomerular circuit inhibits mitral and tufted cell excitatory neurons in distant glomeruli (Aungst et al., 2003; Shirley et al., 2010; Liu et al., 2013, 2016; Whitesell et al., 2013; Banerjee et al., 2015). Here, we asked do SACs inhibit PGCs to impact intraglomerular circuitry? For this, we crossed mice expressing GFP under the control of the GAD65gfp mice (a PGC marker; Shao et al., 2009) with mice expressing Crerecombinase under the control of the TH promoter (THcre mice); TH is expressed by all SACs (Kosaka and Kosaka, 2008; Kiyokage et al., 2010). The OBs of the resulting offspring were injected with ChR2-mCherry AAV constructs resulting in GFP-positive PGCs and ChR2expressing SACs. As a result, optical activation of $\mathrm{TH}-$ ChR2 cells selectively excited SACs. PGCs were clamped at $0 \mathrm{mV}$ to optimize detection of IPSCs (Fig. 1A) while activating SACs located at least three glomeruli distant $(>200 \mu \mathrm{m})$. PGCs (and SACs) can receive direct olfactory nerve input or indirect input via ETCs (Shao et al., 2009) assessed by the presence of spontaneous bursts of EPSCs. We did not observe any difference between cells of the direct/indirect olfactory nerve input pathway and data below are pooled.

Selective activation of SACs evoked robust IPSCs in all PGCs recorded. IPSCs were short latency $1.89 \pm 0.04 \mathrm{~ms}$ (range 1.76-1.98 ms; $n=5$ ) and low jitter $119 \pm 15 \mu \mathrm{s}$ (range 89-169 $\mu \mathrm{s} ; n=5$ ) consistent with monosynaptic inhibition. The peak amplitude of the IPSC was 10-20 pA following a brief, single optical activation of SACs (473 
A
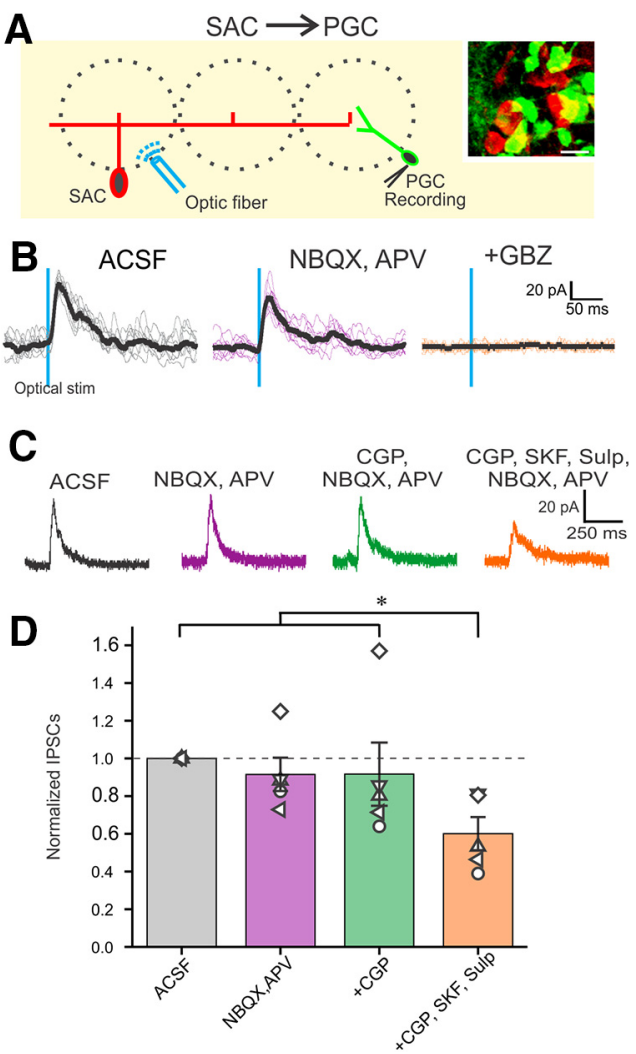

Figure 1. Activation of ChR2-SACs evoked inhibitory response in GAD65gfp PGCs. A, Schematic diagram showing the experimental design of optical stimulation of ChR2-SACs and recording from PGCs. Inset, GAD65gfp (green)- and ChR2-mCherrylabeled THcre neurons in the GL. Scale bar, $10 \mu \mathrm{m}$. B, Voltageclamp recording of a PGC held at $0 \mathrm{mV}$, in ACSF, $10 \mu \mathrm{M} N B Q X$, and $50 \mu \mathrm{M}$ APV, and in further addition of $10 \mu \mathrm{M}$ GBZ. C, Optically evoked IPSCs from a PGC in ACSF (left), NBQX/APV (middle left), further addition of CGP55845 (CGP; middle right), and further addition of D1/D2 blockers SKF83566 and sulpiride (SKF and Sulp, respectively; right). $\boldsymbol{D}$, IPSC amplitude from eight PGCs normalized to ACSF in the presence of NBQX/APV, further addition of CGP55845, and further addition of D1/D2 blockers SKF83566 and sulpiride. NBQX/APV/CGP/SKF/Sulp was significantly different $(* p<0.05)$ from ACSF, NBQX/APV, and NBQX/ APV/CGP. There were no significant differences between ACSF, NBQX/APV, and NBQX/APV/CGP.

$\mathrm{nm}, 2$ ms pulse). IPSCs were abolished by gabazine but impervious to glutamate blockers, which obviates excitatory circuit actions (35.74 $\pm 8.3 \mathrm{pA}$ in ACSF and $33.94 \pm$ $8.78 \mathrm{pA}$ in NBQX/APV; no significant difference; $n=5$; Fig. 1B). GAD65gfp neurons had a resting membrane potential of $-55.25 \pm 2.05 \mathrm{mV}(n=5)$ consistent with previous reports (Shao et al., 2009), with no significant difference in spontaneous spiking activity between ACSF and NBQX/APV $(2.5 \pm 0.7$ spikes/s in ACSF; $2.2 \pm 0.7$ spike/s in NBQX/APV; no significant difference; $n=5$ ). Because GAD65gfp neurons have a high input resistance of $673 \mathrm{M} \Omega$ (Shao et al., 2009), an optically evoked IPSC should generate sufficient hyperpolarization to inhibit spiking. Indeed, optical activation of SACs also completely eliminated spontaneous PGCs spiking (Fig. 2A,D). Conceivably, this could be because of indirect effects as
SACs inhibit ETCs, which might reduce excitation of PGCs. Arguing against this, however, addition of NBQX/ APV, which blocks ETC $\rightarrow$ PGC excitation did not alter SAC $\rightarrow$ PGC IPSPs or spontaneous PGC spiking $(n=4$; Fig. 2B,D-F). DA increases $I_{\mathrm{h}}$ in ETCs causing rebound excitation, increasing ETC excitatory drive to PGCs (Liu et al., 2013). However, addition of DA D1 and D2 receptor blockers reduced SAC-evoked IPSCs in PGCs (as described in the section "GABAB and DA in glomerular inhibitory circuits"). Together these results indicate that SACs inhibit PGCs in distant glomeruli by direct activation of $\mathrm{GABA}_{\mathrm{A}}$ receptors.

\section{On activity engages interglomerular inhibition of intraglomerular circuits}

Can interglomerular inhibition of intraglomerular circuits be elicited by ON input? To explore this, we recorded from GAD65gfp + cells while electrically stimulating the olfactory nerve 3-4 glomeruli caudal to the recorded cell. As ON axons do not "loop-back" rostrally over this distance, this experimental configuration activates the interglomerular circuitry and obviates ON synapses on the recorded PGC. Stimulating ON in this configuration activated interglomerular projections and evoked robust IPSCs in the recorded cell but did not evoke short latency EPSCs, confirming the absence of direct ON synapses. Interglomerular-evoked IPSCs had a latency of $5.45 \pm$ $0.21 \mathrm{~ms}$ (range from 4.83 to $5.93 \mathrm{~ms}$ ) with jitter of $825 \pm$ $190 \mu \mathrm{s}$ (range from 314 to $1256 \mu \mathrm{s}$ ) consistent with a polysynaptic $\mathrm{ON} \rightarrow \mathrm{SAC} \rightarrow \mathrm{PGC}$ interglomerular circuit. IPSCs were completely blocked by GBZ (15.89 $\pm 4.85 \mathrm{pA}$ in ACSF vs $0 \pm 0.32$ in GBZ; $p<0.01 ; n=5$; Fig. 3 ). These findings show that sensory signals can activate the interglomerular circuit to suppress intraglomerular PGCs in distant glomeruli.

\section{PGCs inhibit MCs and SACs}

MCs receive monosynaptic ON input, which is augmented by di-synaptic excitatory inputs from ETCs. These excitatory currents generate long-lasting depolarizing (LLD) excitation in MCs (Carlson et al., 2000; De Saint Jan et al., 2009; Najac et al., 2011; Gire et al., 2012; Shao et al., 2012). The onset of this compound EPSC is followed by an IPSC with latency $6.6 \mathrm{~ms}$ and jitter $432 \mu \mathrm{s}$ (Shao et al., 2012). This inhibitory current shortens the duration of the LLD and is blocked by intraglomerular application of gabazine (Shao et al., 2012), indicating that it is because of glomerular GABAergic interneurons. Although the inhibition is generally attributed to PGCs (Gire and Schoppa, 2009; Shao et al., 2012, 2013; Najac et al., 2015), SACs also generate potent monosynaptic inhibition of MCs (Aungst et al., 2003; Shirley et al., 2010; Liu et al., 2013, 2016; Whitesell et al., 2013; Banerjee et al., 2015). Indeed, the only evidence for monosynaptic $P G C \rightarrow M C$ inhibition is a report based on a small sample of PGC $\rightarrow$ MC paired recordings (Najac et al., 2015).

To seek additional evidence, ChR2 was expressed in GAD65cre neurons by AAV injection into the GL. ChR2 was activated by laser light ( $473 \mathrm{~nm}, 2 \mathrm{~ms}$ pulses) delivered via $25 \mu \mathrm{m}$ fiber optic placed over a glomerulus 

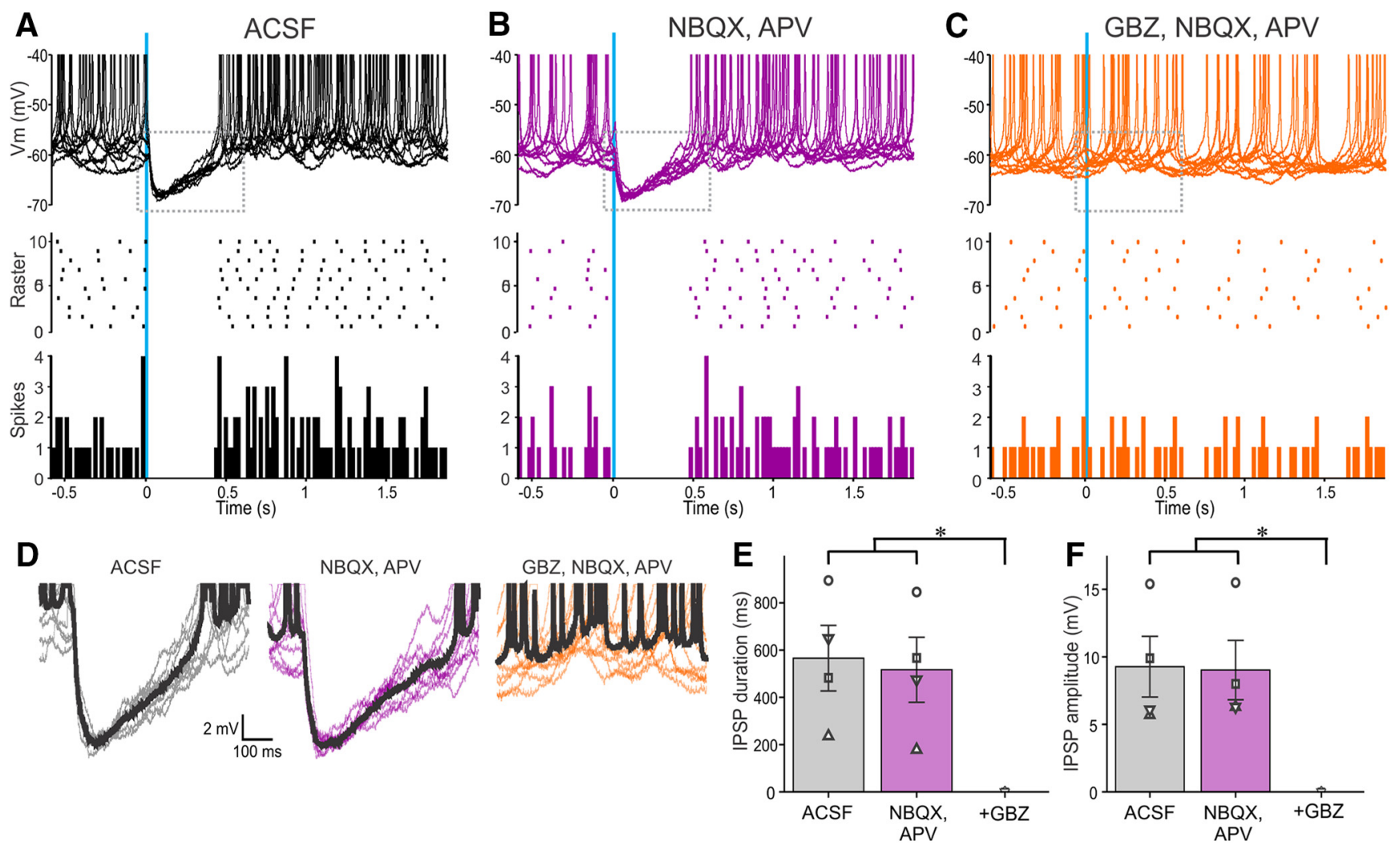

Figure 2. Activation of ChR2-SACs inhibits PGC output. $\boldsymbol{A}-\boldsymbol{C}$, Ten superimposed current-clamp traces showing PGC responses to brief optical stimulation (vertical blue bar) of ChR2-SACs in $(\boldsymbol{A})$ ACSF, $(\boldsymbol{B}) 10 \mu \mathrm{M}$ NBQX, and $50 \mu \mathrm{m}$ APV and $(\boldsymbol{C})$ with further addition of $10 \mu \mathrm{M}$ GBZ. The raster plot $(\boldsymbol{A}-\boldsymbol{C})$ in the middle is from the cell in the top. The bottom $(\boldsymbol{A}-\boldsymbol{C})$ shows a population PSTH plot representing averaged spike data in four PGCs. $\boldsymbol{D}$, Traces showing IPSPs evoked by optical stimulation of ChR2-SACs from the dotted rectangles in the corresponding top panels in $\boldsymbol{A}-\boldsymbol{C}$. The thick black trace represents the average of the 10 traces. $\boldsymbol{E}$, Population data from four PGCs showing the effects of stimulation in ACSF, NBQX/APV, or NBQX/APV plus GBZ on IPSP duration. NBQX/ APV/GBZ was significantly different $(* p<0.01)$ from the groups ACSF and NBQX/APV. There were no significant differences between the groups ACSF and NBQX/APV. $\boldsymbol{F}$, Population data from four PGCs showing the effects of stimulation in ACSF, NBQX/APV, or NBQX/APV plus GBZ on IPSP amplitude. NBQX/APV/GBZ was significantly different $(* p<0.01)$ from the groups ACSF and NBQX/APV. There were no significant differences between the groups ACSF and NBQX/APV.

containing the dendrite of a patched, Lucifer yellow filled, MC (Fig. 4A). PGCs preferentially express GAD65 (Parrish-Aungst et al., 2011), but this isoenzyme is also expressed by some SACs (Parrish-Aungst et al., 2007), which may also have been activated. Arguing against this, however, is the fact that in all GAD65-ChR2 cell $\rightarrow$ MC experiments inhibitory currents were evoked only when the optical fiber targeted the glomerulus containing the recorded MC's apical dendrite. When the fiber was moved to nearby glomeruli responses were not evoked. This indicates that contamination by GAD65-expressing SACs was negligible (see Discussion).
A

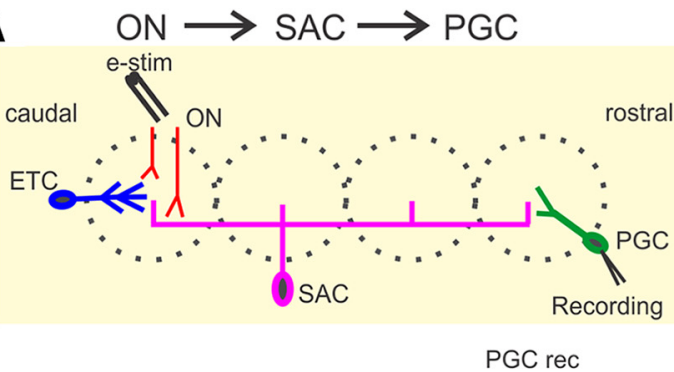

B

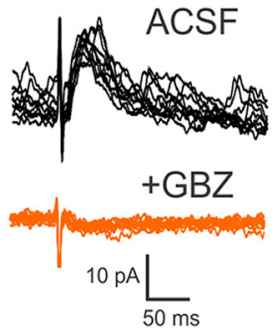

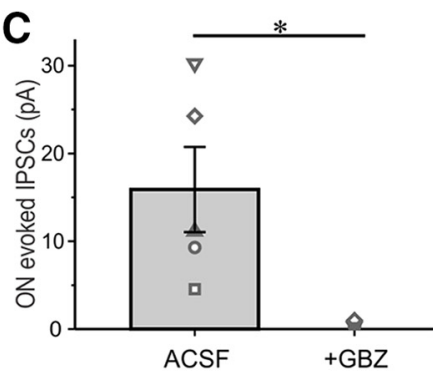

Figure 3. E-stimulation of the olfactory nerve evokes PGC inhibitory responses in distant glomeruli. $\boldsymbol{A}$, Schematic diagram showing the experimental design of electrical stimulation to the olfactory nerve layer (ONL) and PGC recording in a distant glomerulus. $\boldsymbol{B}$, Nerve stimulation evokes IPSCs in a PGC held at $0 \mathrm{mV}$ four glomeruli away from the stimulation site. Responses are abolished by the addition of $10 \mu \mathrm{M}$ GBZ. C, Population data showing olfactory nerve stimulation evoked IPSC amplitude from five PGCs at least four glomeruli from the stimulation site in ACSF and in $10 \mu \mathrm{m}$ GBZ. Statistical significance $* p<0.01$. 

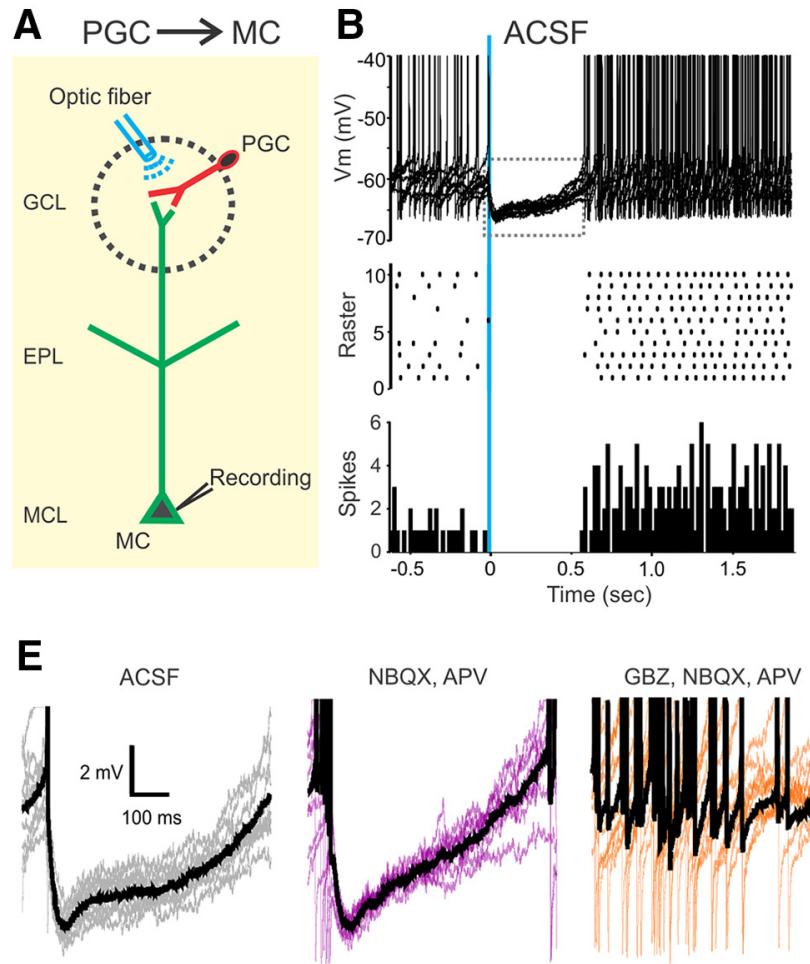
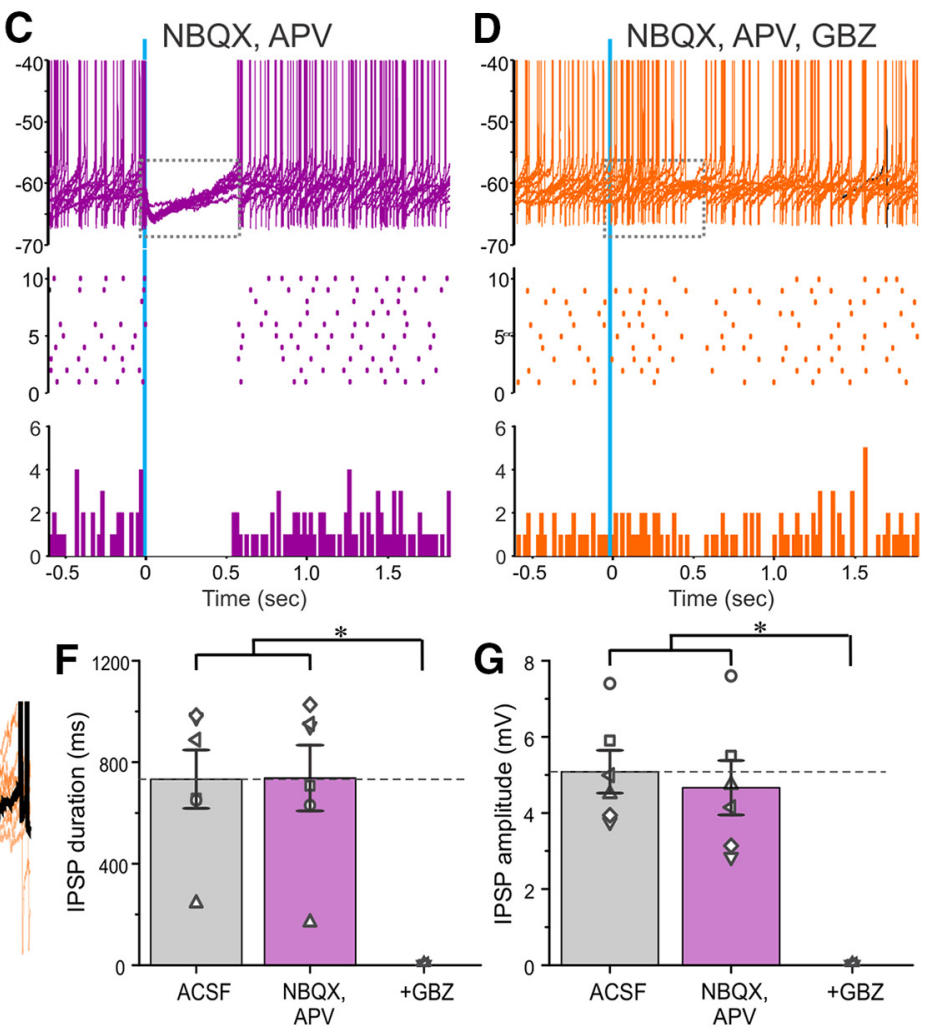

Figure 4. PGCs inhibit MC output. $\boldsymbol{A}$, Schematic diagram showing the experimental design of optical stimulation of ChR2-PGCs and $M C$ recording. $\boldsymbol{B}-\boldsymbol{D}$, Ten superimposed current-clamp sweeps showing long-lasting $M C$ inhibition to brief optical stimulation (vertical blue bar) of CHR2-PGCs in ACSF (B), in the presence of $10 \mu \mathrm{M}$ NBQX and $50 \mu \mathrm{M}$ APV (C). Addition of $10 \mu \mathrm{m}$ GBZ blocks the inhibition of MCs $(\boldsymbol{D})$. The raster plot $(\boldsymbol{B}-\boldsymbol{D})$ in the middle is from the cell in the top. The bottom $(\boldsymbol{B}-\boldsymbol{D})$ shows a population PSTH of averaged spike data from six MCs. $\boldsymbol{E}$, Traces showing IPSPs evoked by optical stimulation of ChR2-PGCs expanded from the dotted rectangles in the corresponding top in $\boldsymbol{B}-\boldsymbol{D}$. The thick black trace represents the average IPSP of the 10 sweeps. $\boldsymbol{F}$, Population data from six MCs shows the effect of PGC stimulation on MCs in ACSF, NBQX, and APV, or NBQX/APV plus GBZ on IPSP duration. NBQX/APV/GBZ was significantly different $(* p<0.0001)$ from the groups ACSF and NBQX/APV. There were no significant differences between the groups ACSF and NBQX/APV. G, Population data from six MCs shows the effect of PGC stimulation on MCs in ACSF, NBQX, and APV, or NBQX-APV plus GBZ on IPSP amplitude. NBQX/APV/GBZ was significantly different $(* p<0.0001)$ from the groups ACSF and NBQX/APV. There were no significant differences between the groups ACSF and NBQX/APV.

Activation of PGCs generated hyperpolarization in SACs that was blocked by gabazine, but not glutamate receptor blockers $(5.08 \pm 0.56 \mathrm{mV}$ in ACSF and $4.66 \pm$ $0.71 \mathrm{mV}$ in NBQX/APV; no significant difference; $n=6$; Fig. $4 E, F$; resting membrane potential $-57.2 \pm 2.33 \mathrm{mV}$ ). IPSP latencies were $2.23 \pm 0.06 \mathrm{~ms}$ (range $1.96-2.38 \mathrm{~ms}$; $n=6$ ) with jitter of $191.36 \pm 15.55 \mu \mathrm{S}$ (range 139.39$231.13 \mu \mathrm{s} ; n=6$ ) consistent with PGC $\rightarrow$ MC monosynaptic inhibition. Activation of PGCs also caused immediate, sustained inhibition of spontaneous MCs spiking ( $n=6$; Fig. $4 B$ ). Inhibition was long lasting (733 \pm $115 \mathrm{~ms}$ in ACSF and $738 \pm 130 \mathrm{~ms}$ in NBQX/APV; no significant difference; $n=6$; Fig. $4 E, F$ ), exceeding the brief 2 ms optical activation of PGCs. This is consistent with previous reports that $\mathrm{MC}$ intrinsic membrane properties prolong the duration of synaptic inhibition (Liu et al., 2016). Together, the preceding results demonstrate that both PGCs and SACs directly inhibit MCs and that MC intrinsic properties prolong these inhibitory actions (Liu et al., 2016). Thus, both intraglomerular and interglomerular inhibitory circuits potently regulate MCs.
To determine whether PGCs also inhibit SACs, GAD65cre mice were crossed with mice expressing GFP under control of the TH promoter. ChR2 was introduced into GAD65 neurons by AAV injection. As noted, some ( 20\%) SACs express GAD65 and thus could provide $\mathrm{SAC} \rightarrow \mathrm{SAC}$ inhibition. However, as there were no responses to interglomerular activation in the $\mathrm{PGC} \rightarrow \mathrm{MC}$ experiments (above), SAC contamination appears functionally negligible, thus ChR2 responsive GAD65expressing cells are assumed to be mainly PGCs. Optical activation of PGCs evoked robust IPSCs in all recorded THgfp $^{+}$SACs (Fig. $5 A ; n=5$ ). IPSCs were short latency $1.85 \pm 0.05 \mathrm{~ms}$ (range $1.77-2.01 \mathrm{~ms} ; n=5$ ) with low jitter $142 \pm 38 \mu \mathrm{s}$ (range 43-274 $\mu \mathrm{s} ; n=5$ ) consistent with monosynaptic PGC $\rightarrow$ SAC inhibition. IPSCs were abolished by gabazine (10 $\mu \mathrm{M}$ GBZ), but unaltered by ionotropic glutamate receptor block $(29.8 \pm 14.66 \mathrm{pA}$ in ACSF vs $27.8 \pm 14.78 \mathrm{pA}$ in NBQX/APV, no significant difference; $n=5$; Fig. $5 B$ ).

SACs have spontaneous, as well as ON- and ETCevoked action potentials. Brief $(2 \mathrm{~ms})$ optical activation of 
A

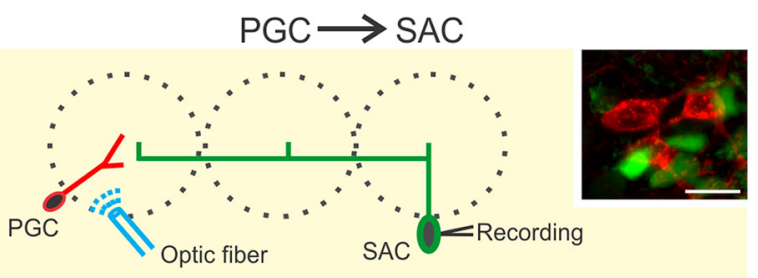

B

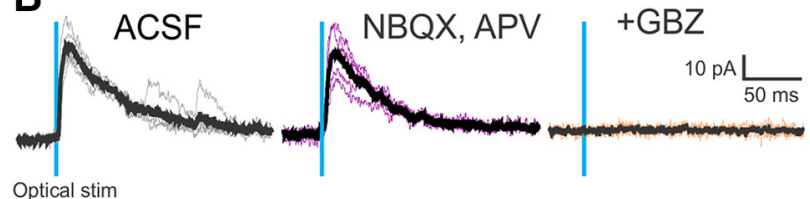

Optical stim

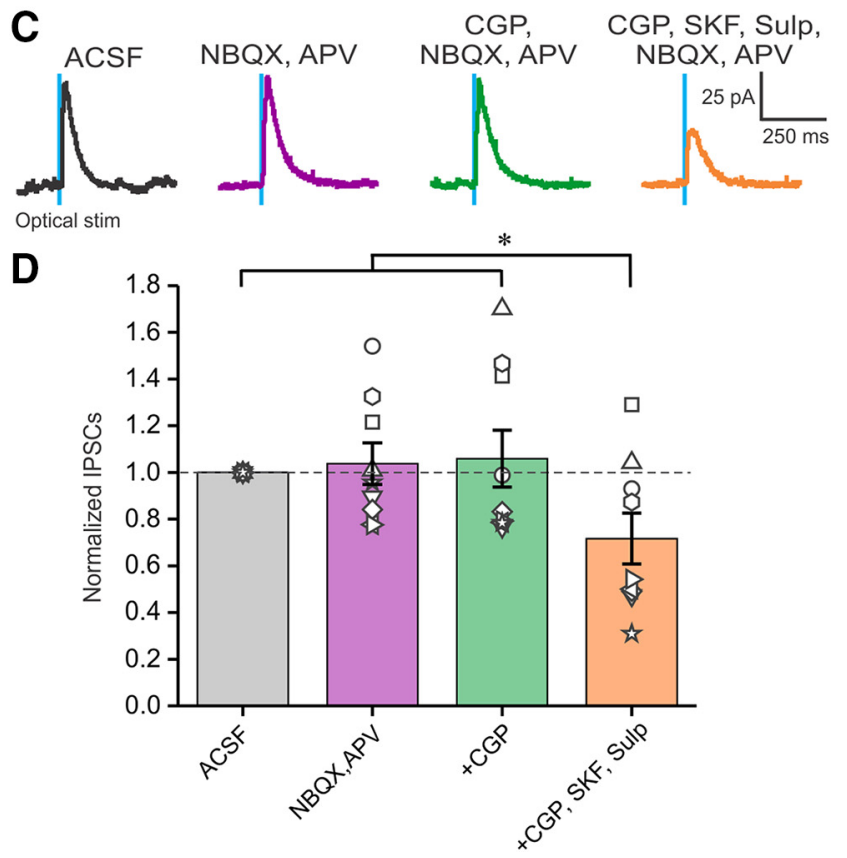

Figure 5. Activation of ChR2-PGCs evokes inhibitory responses in THgfp-positive SACs. $\boldsymbol{A}$, Schematic diagram showing the experimental design of optical stimulation of ChR2-PGCs and recording from SACs. Inset, THgfp- (green) and ChR2-mCherry-labeled GAD65cre neurons in the GL. Scale bar, $10 \mu \mathrm{m}$. B, Voltage-clamp recording from an SAC held at $0 \mathrm{mV}$ exhibiting optical evoked IPSC in ACSF (left), in NBQX/APV (middle), and in further addition of GBZ (right). The thick black trace represents the average IPSC of 10 sweeps. C, Optically evoked IPSCs from SAC in ACSF (left), NBQX/ APV (middle left), further addition of CGP55845 (CGP; middle right), and further addition of D1/D2 blockers SKF83566 and sulpiride (SKF and Sulp, respectively; right). D, IPSC amplitude from nine SACs normalized to ACSF in the presence of NBQX/APV, further addition of CGP55845, and further addition of D1/D2 blockers SKF83566 and sulpiride. NBQX/APV/ CGP/SKF/Sulp was significantly different $(* p<0.05)$ from ACSF, NBQX/APV, and NBQX/APV/CGP. There were no significant differences between ACSF, NBQX/APV, and NBQX/ APV/CGP.

PGCs evoked a $6.52 \pm 1.05 \mathrm{mV}$ IPSP lasting for $564 \pm$ $136 \mathrm{~ms}(n=5$; Fig. $6 A, D-F)$ and completely eliminated spontaneous SAC spiking. To isolate SACs from ETC glutamatergic drive NBQX and APV were added to the bath. Consistent with ETC excitation of SACs (Hayar et al., 2004), this reduced SAC spontaneous spiking by $\sim 7.2 \%$ (4.8 \pm 1.1 spike/s in ACSF, $4.5 \pm 1.5$ spikes $/ \mathrm{s}$ in NBQX/APV; no significant difference; $n=5$; Fig. $6 A, B$ ). However, PGC activation still evoked a robust IPSP and eliminated residual spontaneous SAC spiking $(n=5$; Fig. $6 B-F)$. This shows that PGCs activate postsynaptic $\mathrm{GABA}_{\mathrm{A}}$ receptors to directly inhibit SACs.

\section{GABA $_{B}$ and DA in glomerular inhibitory circuits}

Glomerular circuitry also contains $\mathrm{GABA}_{\mathrm{B}}$ receptors that can act at presynaptic and/or postsynaptic $\mathrm{GABA}_{\mathrm{B}}$ receptors to modulate glomerular circuits (Wachowiak and Cohen, 1999; Aroniadou-Anderjaska et al., 2000; Ennis et al., 2001; McGann et al., 2005; Vucini et al., 2006; Karpuk and Hayar, 2008; Vaaga et al., 2017). Since both PGCs and SACs release GABA, optically evoked responses in the corresponding neuron could be influenced by $\mathrm{GABA}_{\mathrm{B}}$ receptors. However, addition of a $\mathrm{GABA}_{\mathrm{B}}$ blocker CGP55845 (10 $\mu \mathrm{M})$ had no effect on the duration, amplitude, or latency/jitter of the $\mathrm{SAC} \rightarrow \mathrm{PGC}$ evoked IPSCs $(n=5$; Fig. $1 C, D)$ or the PGC $\rightarrow$ SAC evoked IPSCs $(n$ $=5$; Fig. 5C,D). SACs release DA as well as GABA (Liu et al., 2013). DA tonically inhibits presynaptic terminals of the olfactory nerve (Ennis et al., 2001) and modulates ETC membrane properties (Liu et al., 2013). Thus, tonic DA release may modulate SAC-evoked PGC responses and/or PGC evoked SAC responses. To test this D1/D2 blockers (10 $\mu \mathrm{M}$ SKF83566, $100 \mu \mathrm{M}$ sulpiride) were added along with glutamate receptor blockade. D1 and D2 blockers decreased SAC $\rightarrow$ PGC IPSC amplitude by $\sim 40 \%(22.27 \pm 2.16 \mathrm{pA}$ in ACSF and $12.73 \pm 1.14 \mathrm{pA}$ in D1/D2 blockers; $n=5, p<0.05$; Fig. $1 C, D)$ and PGC$\rightarrow$ SAC IPSC amplitude by $23 \%$ (48.6 $\pm 11.7 \mathrm{pA}$ in ACSF and $37.4 \pm 11.7 \mathrm{pA}$ in D1/D2 blockers; $p<0.05 ; n=9$; Fig. $6 C, D)$. This tonic action of DA, which enhances inhibition at the $\mathrm{SAC} \rightarrow \mathrm{PGC}$ and the $\mathrm{PGC} \rightarrow \mathrm{SAC}$ synapses, may be presynaptic or postsynaptic or both.

\section{Discussion}

Glomeruli regulate odor signals at the initial stage of synaptic integration in the olfactory system (for review, see Ennis et al., 2014). Throughput is initiated by olfactory nerve excitation of output neurons, MCs/TCs, and is strongly modulated by glomerular inhibitory circuits. The major glomerular inhibitory neurons are GABAergic PGCs and GABAergic/DAergic SACs. They provide presynaptic inhibition of ON synapses and postsynaptic inhibition of $\mathrm{MCs} / \mathrm{TCs}$. PGCs provide mainly intraglomerular inhibition while SACs mediate both intraglomerular and interglomerular inhibition of neurons in other glomeruli.

PGCs and SACs receive mono- (type 1) or polysynaptic (type 2) (Toida et al., 1994, 1998, 2000; Kosaka et al., 1995, 1997; Shao et al., 2009; Kiyokage et al., 2010) excitatory inputs from olfactory nerve terminals (Shao et al., 2009; Liu et al., 2013) and monosynaptic excitation from OB projection neurons (Hayar et al., 2004). Together, glomerular inhibitory and excitatory neurons form complex, heterogeneous circuits. Here we show that PGCs and SACs inhibit each other, as well as glomerular output neurons. This adds to the processing richness of glomer- 

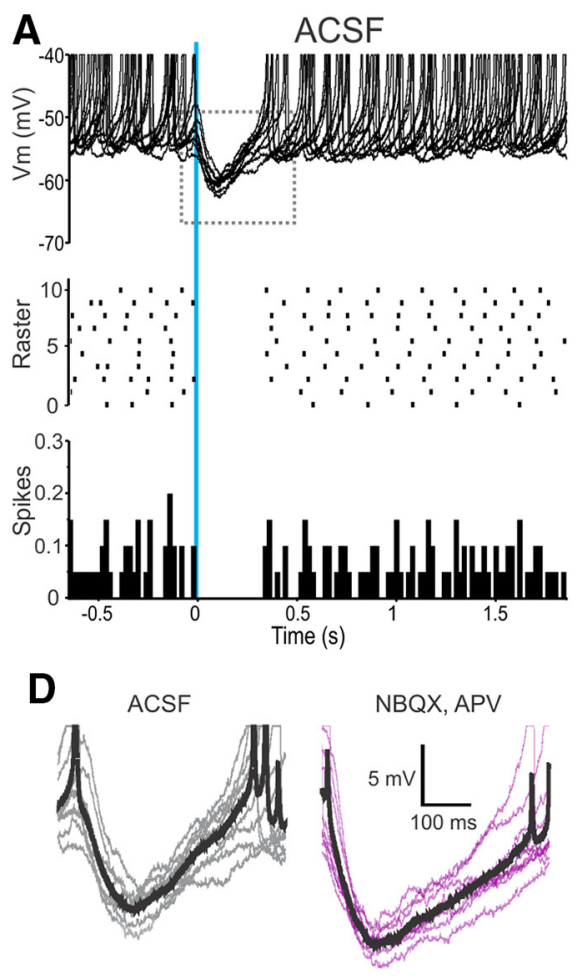
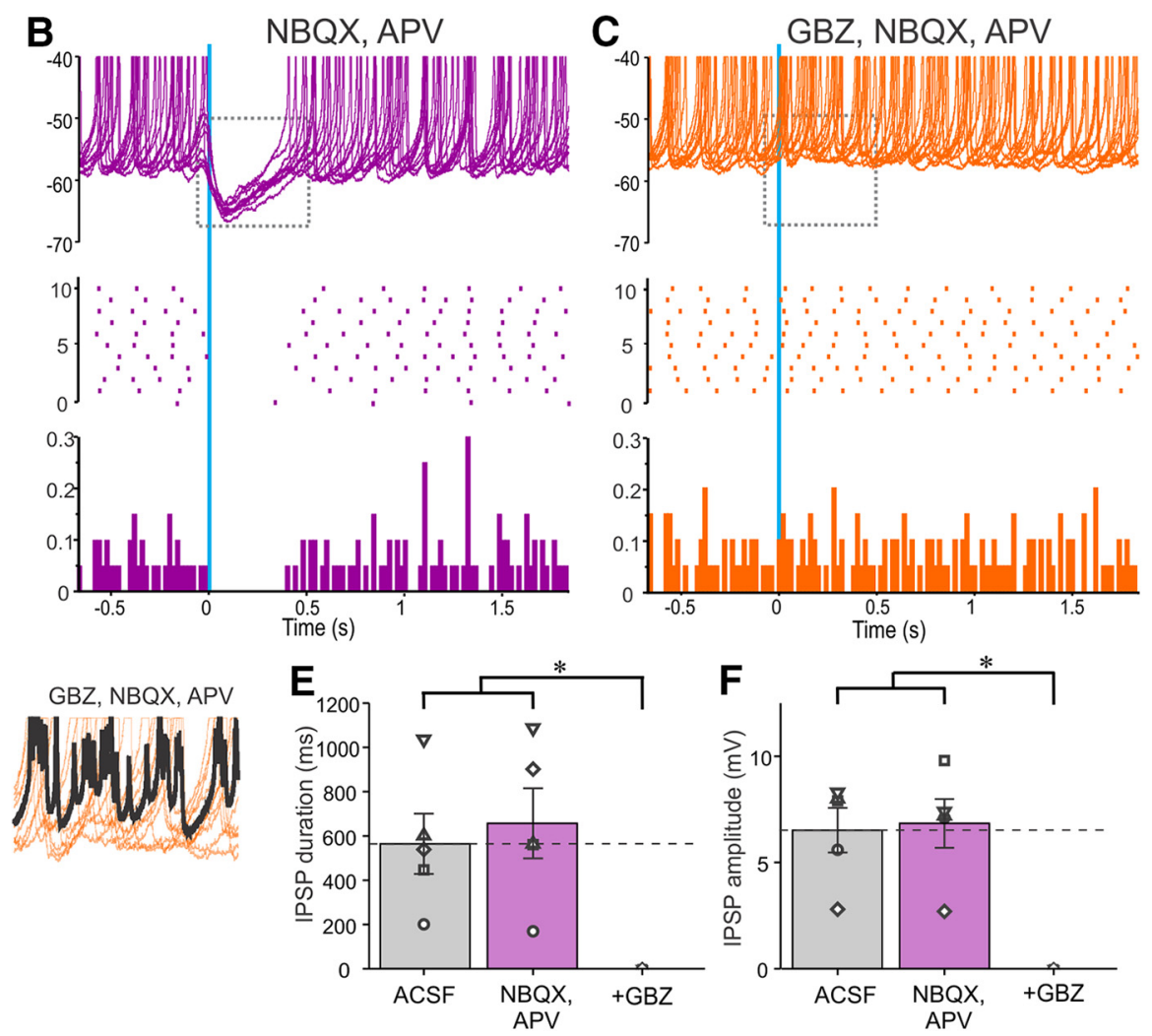

Figure 6. Activation of ChR2-PGCs inhibits SAC output. $\boldsymbol{A}-\boldsymbol{C}$, Ten superimposed current-clamp traces showing SAC responses to brief optical stimulation (vertical blue bar) of ChR2-PGCs in $(\boldsymbol{A})$ ACSF, $(\boldsymbol{B}) 10 \mu \mathrm{M}$ NBQX, and $50 \mu \mathrm{M}$ APV and $(\boldsymbol{C})$ with further addition of $10 \mu \mathrm{M}$ GBZ. The raster plot $(\boldsymbol{A}-\boldsymbol{C})$ in the middle is from the cell in the top. The bottom $(\boldsymbol{A}-\boldsymbol{C})$ shows a population PSTH plot representing averaged spike data from five SACs. $\boldsymbol{D}$, Traces showing IPSPs evoked by optical stimulation of ChR2-PGCs expanded from the dotted rectangles in the corresponding top panels in $\boldsymbol{A}-\boldsymbol{C}$. The thick black trace represents the average IPSP of the 10 traces. $\boldsymbol{E}$, Population data from five SACs showing the effects of PGC stimulation on SACs in ACSF, NBQX/APV, or NBQX/APV plus GBZ on IPSP duration. NBQX/APV/GBZ was significantly different $(* p<0.01)$ from the groups ACSF and NBQX/APV. There were no significant differences between the groups ACSF and NBQX/APV. F, Population data from five SACs showing the effects of PGC stimulation of SACs in ACSF, NBQX/APV, or NBQX/APV plus GBZ on IPSP amplitude. NBQX/APV/GBZ was significantly different (*p $<0.001)$ from the groups ACSF and NBQX/APV. There were no significant differences between the groups ACSF and NBQX/APV.

ular networks and demonstrates that glomerular inhibitory circuits potently modulate neural processing of odorant stimuli.

\section{PGCs inhibit MCs}

MCs receive IPSCs from neurons in glomerular circuits (Shao et al., 2012). Although this is presumed to come from PGCs, there is surprisingly little, direct evidence for $\mathrm{PGC} \rightarrow \mathrm{MC}$ monosynaptic inhibition, primarily a small sample of paired $\mathrm{PGC} \rightarrow \mathrm{MC}$ recordings (Najac et al., 2015). To seek additional evidence, we expressed ChR2 in GAD65cre cells (Parrish-Aungst et al., 2007). This evoked robust IPSCs in MCs that were completely blocked by a $\mathrm{GABA}_{\mathrm{A}}$ receptor antagonist. IPSCs had latencies $(<2 \mathrm{~ms})$ and jitter $(<200 \mu \mathrm{s})$ consistent with a monosynaptic connection. Moreover, they were impervious to glutamate receptor blockers, thus obviating excitatory circuit effects. GAD65 is expressed by all PGCs and some SACs ( 20\%; Parrish-Aungst et al., 2007). Thus some of the inhibitory currents might be attributable to SACs. However, inhibition was evoked only when the 25 $\mu \mathrm{m}$ fiber targeted the glomerulus containing the dendritic tuft of the recorded MC. Activation of GAD65-ChR2 cells 2-4 glomeruli distant did not evoke any responses in MCs.

There are several possible reasons why GAD65expressing SACs may not contribute to MC inhibition. First, the subset of GAD65-expressing SACs (ParrishAungst et al., 2007) may be too few in number to generate detectable IPSCs in MCs. Second, some SACs innervate only 4-7 nearby glomeruli. These "oligoglomerular" SACs (Kiyokage et al., 2010) may correspond to the recently reported short-range projecting DA "axon-initial-segment negative" SACs (Galliano et al., 2018). We stimulated at least three glomeruli distant, which may have been beyond the processes of these SACs even if they did express GAD65-ChR2. Finally, DA neurons are continuously generated and migrate into glomeruli throughout adult life (Luskin, 1993; Lois and Alvarez-Buylla, 1994; Kohwi et al., 2005; De Marchis et al., 2007; Galliano et al., 2018). Immature DA cells express TH promoter activity before expression of TH protein or GAD enzymes (Baker et al., 
2001; De Marchis et al., 2004; Plachez and Puche, 2012). It is conceivable, therefore, that these immature cells transiently express the GAD65 transgene, but do not yet contribute significantly to interglomerular inhibition. Thus, while we cannot exclude a small contribution of GAD65 ${ }^{+}$ SACs to MC inhibition, the parsimonious conclusion is that it is mainly, if not exclusively, because of PGCs.

\section{Mutual PGC-SAC inhibition}

PGCs and SACs are involved in diverse glomerular circuit functions. For example, $\mathrm{GABA}_{\mathrm{B}}$ receptors are expressed on olfactory nerve terminals (Bonino et al., 1999; Panzanelli et al., 2004) and ON excitation of PGCs and SACs may evoke GABA release to cause presynaptic inhibition of sensory input (Wachowiak and Cohen, 1999; Aroniadou-Anderjaska et al., 2000; Murphy et al., 2005; Wachowiak et al., 2005; Pirez and Wachowiak, 2008; Shao et al., 2009). Activation of PGCs and SACs evoke IPSC/Ps in ETCs, as well as MCs/TCs (present study (Aungst et al., 2003; Hayar et al., 2005; Murphy et al., 2005; Whitesell et al., 2013; Banerjee et al., 2015; Najac et al., 2015; Liu et al., 2016). ON terminals have DA D2 presynaptic receptors and tonic and evoked DA release by SACs inhibits sensory inputs (Koster et al., 1999; Wachowiak and Cohen, 1999; Ennis et al., 2001). SACs form the interglomerular circuit, which synapse onto neurons in neighboring and distant glomeruli (Aungst et al., 2003; Kosaka and Kosaka, 2008; Kiyokage et al., 2010; Shirley et al., 2010; Whitesell et al., 2013; Banerjee et al., 2015; Galliano et al., 2018). SACs co-release GABA and DA, which acts postsynaptically on M/TCs and ETCs (Borisovska et al., 2013; Liu et al., 2013, 2016). PGCs form mainly intraglomerular circuits that act in a single glomerulus. Thus, PGCs and SACs have numerous presynaptic and postsynaptic inhibitory targets and play multiple roles shaping glomerular input-output signal processing.

Here, we asked whether there are synaptic interactions between PGCs and SACs. Our findings show that GABA receptor-dependent IPSC/Ps were elicited at both $\mathrm{SAC} \rightarrow \mathrm{PGC}$ and PGC $\rightarrow$ SAC synapses. IPSCs in both circuits had short latency and low jitter (latency $<2 \mathrm{~ms}$, jitter $<200 \mu \mathrm{s})$ indicative of monosynaptic connections. SAC $\rightarrow$ PGC inhibition was evoked by activation of distant glomeruli, showing that interglomerular SAC projections target PGCs, as well as ETCs and MCs (Aungst et al., 2003; Shirley et al., 2010; Borisovska et al., 2013; Liu et al., 2013, 2016; Whitesell et al., 2013; Banerjee et al., 2015). Our findings further show that interglomerular connectivity is functionally relevant, as activation of ON inputs to one glomerulus evoke IPSC/Ps in PGCs of distant glomeruli.

Olfactory sensory input is dynamic, regulated by the respiratory and sniffing behavior of the animal, generating episodic excitatory input to the glomerular circuitry. In this study we show that olfactory nerve input, in addition to excitatory-inhibitory neuron synapses and the reciprocal excitatory-excitatory connections between ETCs/MCs (Hayar et al., 2004; De Saint Jan et al., 2009; Najac et al., 2011), can also elicit activity within the robust inhibitory to inhibitory circuits during olfactory sensory processing. Inhibitory connections between PGCs and SACs may regulate glomerular circuit dynamics in odor processing. The interglomerular circuit could generate opposing actions on MCs in different, distant glomeruli: SACs directly inhibit MCs and ETCs reducing their output (Liu et al., 2016) but they also inhibit PGCs, which could disinhibit ETCs and MCs, thus increasing their excitability. Synchronous interglomerular network activation (Aungst et al., 2003; Shirley et al., 2010; Liu et al., 2016) generates net inhibition of MCs. In vivo, however, odorant stimuli elicit unique patterns of suppression and excitation in subsets of spatially intermingled glomeruli (Economo et al., 2016). Odorant activation of the interglomerular circuit may generate net suppression of some glomerular subsets and net activation of others depending on the nature and context of the odorant stimulus. Reciprocal PGC-SAC inhibition may contribute to a network dynamic that determines the balance of glomerular excitation and inhibition in response to different odorants, including potentially modulating temporal dynamics in the circuit. How these networks are modulated by input frequency, as in sniffing, remains to be explored.

\section{References}

Aroniadou-Anderjaska V, Zhou FM, Priest CA, Ennis M, Shipley MT (2000) Tonic and synaptically evoked presynaptic inhibition of sensory input to the rat olfactory bulb via GABA(B) heteroreceptors. J Neurophysiol 84:1194-1203.

Aungst JL, Heyward PM, Puche AC, Karnup SV, Hayar A, Szabo G, Shipley MT (2003) Centre-surround inhibition among olfactory bulb glomeruli. Nature 426:623-629.

Baker H, Liu N, Chun HS, Saino S, Berlin R, Volpe B, Son JH (2001) Phenotypic differentiation during migration of dopaminergic progenitor cells to the olfactory bulb. J Neurosci 21:8505-8513.

Banerjee A, Marbach F, Anselmi F, Koh MS, Davis MB, Garcia da Silva P, Delevich K, Oyibo HK, Gupta P, Li B, Albeanu DF (2015) An interglomerular circuit gates glomerular output and implements gain control in the mouse olfactory bulb. Neuron 87:193-207.

Bonino M, Cantino D, Sassoè-Pognetto M (1999) Cellular and subcellular localization of gamma-aminobutyric acidB receptors in the rat olfactory bulb. Neurosci Lett 274:195-198.

Borisovska M, Bensen AL, Chong G, Westbrook GL (2013) Distinct modes of dopamine and GABA release in a dual transmitter neuron. J Neurosci 33:1790-1796.

Brill J, Shao Z, Puche AC, Wachowiak M, Shipley MT (2016) Serotonin increases synaptic activity in olfactory bulb glomeruli. J Neurophysiol 115:1208-1219.

Burton SD, LaRocca G, Liu A, Cheetham CE, Urban NN (2017) Olfactory bulb deep short-axon cells mediate widespread inhibition of tufted cell apical dendrites. J Neurosci 37:1117-1138.

Carlson GC, Shipley MT, Keller A (2000) Long-lasting depolarizations in mitral cells of the rat olfactory bulb. J Neurosci 20:2011-2021.

De Marchis S, Temoney S, Erdelyi F, Bovetti S, Bovolin P, Szabo G, Puche AC (2004) GABAergic phenotypic differentiation of a subpopulation of subventricular derived migrating progenitors. Eur $\mathrm{J}$ Neurosci 20:1307-1317.

De Marchis S, Bovetti S, Carletti B, Hsieh YC, Garzotto D, Peretto P, Fasolo A, Puche AC, Rossi F (2007) Generation of distinct types of periglomerular olfactory bulb interneurons during development and in adult mice: implication for intrinsic properties of the subventricular zone progenitor population. J Neurosci 27:657-664. 
De Saint Jan D, Hirnet D, Westbrook GL, Charpak S (2009) External tufted cells drive the output of olfactory bulb glomeruli. J Neurosci 29:2043-2052.

Economo MN, Hansen KR, Wachowiak M (2016) Control of mitral/ tufted cell output by selective inhibition among olfactory bulb glomeruli. Neuron 91:397-411.

Ennis M, Puche AC, Holy TE, Shipley MT (2014) The olfactory system. In: The rat nervous system, Ed 4 (Paxinos G, ed). New York: Elsevier.

Ennis M, Zhou FM, Ciombor KJ, Aroniadou-Anderjaska V, Hayar A, Borrelli E, Zimmer LA, Margolis F, Shipley MT (2001) Dopamine D2 receptor-mediated presynaptic inhibition of olfactory nerve terminals. J Neurophysiol 86:2986-2997.

Eyre MD, Antal M, Nusser Z (2008) Distinct deep short-axon cell subtypes of the main olfactory bulb provide novel intrabulbar and extrabulbar GABAergic connections. J Neurosci 28:8217-8229.

Galliano E, Franzoni E, Breton M, Chand AN, Byrne DJ, Murthy VN, Grubb MS (2018) Embryonic and postnatal neurogenesis produce functionally distinct subclasses of dopaminergic neuron. eLife 7:e32373.

Gire DH, Schoppa NE (2009) Control of on/off glomerular signaling by a local GABAergic microcircuit in the olfactory bulb. J Neurosci 29:13454-13464.

Gire DH, Franks KM, Zak JD, Tanaka KF, Whitesell JD, Mulligan AA, Hen R, Schoppa NE (2012) Mitral cells in the olfactory bulb are mainly excited through a multistep signaling path. $J$ Neurosci 32:2964-2975.

Hayar A, Shipley MT, Ennis M (2005) Olfactory bulb external tufted cells are synchronized by multiple intraglomerular mechanisms. J Neurosci 25:8197-8208.

Hayar A, Karnup S, Ennis M, Shipley MT (2004) External tufted cells: a major excitatory element that coordinates glomerular activity. $J$ Neurosci 24:6676-6685.

Karpuk N, Hayar A (2008) Activation of postsynaptic GABAB receptors modulates the bursting pattern and synaptic activity of olfactory bulb juxtaglomerular neurons. J Neurophysiol 99:308-319.

Kiyokage E, Pan YZ, Shao Z, Kobayashi K, Szabo G, Yanagawa Y, Obata K, Okano H, Toida K, Puche AC, Shipley MT (2010) Molecular identity of periglomerular and short axon cells. J Neurosci 30:1185-1196.

Kohwi M, Osumi N, Rubenstein JL, Alvarez-Buylla A (2005) Pax6 is required for making specific subpopulations of granule and periglomerular neurons in the olfactory bulb. J Neurosci 25:69977003.

Kosaka K, Toida K, Margolis FL, Kosaka T (1997) Chemically defined neuron groups and their subpopulations in the glomerular layer of the rat main olfactory bulb: II. Prominent differences in the intraglomerular dendritic arborization and their relationship to olfactory nerve terminals. Neuroscience 76:775-786.

Kosaka K, Aika Y, Toida K, Heizmann CW, Hunziker W, Jacobowitz DM, Nagatsu I, Streit P, Visser TJ, Kosaka T (1995) Chemically defined neuron groups and their subpopulations in the glomerular layer of the rat main olfactory bulb. Neurosci Res 23:73-88.

Kosaka T, Kosaka K (2008) Tyrosine hydroxylase-positive GABAergic juxtaglomerular neurons are the main source of the interglomerular connections in the mouse main olfactory bulb. Neurosci Res 60:349-354.

Koster NL, Norman AB, Richtand NM, Nickell WT, Puche AC, Pixley SK, Shipley MT (1999) Olfactory receptor neurons express D2 dopamine receptors. J Comp Neur 411:666-673.

Letzkus JJ, Wolff SB, Lüthi A (2015) Disinhibition, a circuit mechanism for associative learning and memory. Neuron 88:264-276.

Liu S, Puche AC, Shipley MT (2016) The interglomerular circuit potently inhibits olfactory bulb output neurons by both direct and indirect pathways. J Neurosci 36:9604-9617.

Liu S, Plachez C, Shao Z, Puche A, Shipley MT (2013) Olfactory bulb short axon cell release of gaba and dopamine produces a temporally biphasic inhibition-excitation response in external tufted cells. J Neurosci 33:2916-2926.

Liu S, Shao Z, Puche A, Wachowiak M, Rothermel M, Shipley MT (2015) Muscarinic receptors modulate dendrodendritic inhibitory synapses to sculpt glomerular output. J Neurosci 35:5680-5692.

Lois C, Alvarez-Buylla A (1994) Long-distance neuronal migration in the adult mammalian brain. Science 264:1145-1148.

Luskin MB (1993) Restricted proliferation and migration of postnatally generated neurons derived from the forebrain subventricular zone. Neuron 11:173-189.

McGann JP, Pírez N, Gainey MA, Muratore C, Elias AS, Wachowiak M (2005) Odorant representations are modulated by intra- but not interglomerular presynaptic inhibition of olfactory sensory neurons. Neuron 48:1039-1053.

Murphy GJ, Darcy DP, Isaacson JS (2005) Intraglomerular inhibition: signaling mechanisms of an olfactory microcircuit. Nat Neurosci 8:354-364.

Najac M, De Saint JD, Reguero L, Grandes P, Charpak S (2011) Monosynaptic and polysynaptic feed-forward inputs to mitral cells from olfactory sensory neurons. J Neurosci 31:8722-8729.

Najac M, Sanz Diez A, Kumar A, Benito N, Charpak S, De Saint Jan D (2015) Intraglomerular lateral inhibition promotes spike timing variability in principal neurons of the olfactory bulb. J Neurosci 35:4319-4331.

Panzanelli P, Homanics GE, Ottersen OP, Fritschy JM, SassoèPognetto M (2004) Pre- and postsynaptic GABA receptors at reciprocal dendrodendritic synapses in the olfactory bulb. Eur $\mathrm{J}$ Neurosci 20:2945-2952.

Parrish-Aungst S, Shipley MT, Erdelyi F, Szabo G, Puche AC (2007) Quantitative analysis of neuronal diversity in the mouse olfactory bulb. J Comp Neur 501:825-836.

Parrish-Aungst S, Kiyokage E, Szabo G, Yanagawa Y, Shipley MT, Puche AC (2011) Sensory experience selectively regulates transmitter synthesis enzymes in interglomerular circuits. Brain Res 1382:70-76.

Pinching AJ, Powell TP (1971) The neuropil of the glomeruli of the olfactory bulb. J Cell Sci 9:347-377.

Pirez N, Wachowiak M (2008) In vivo modulation of sensory input to the olfactory bulb by tonic and activity-dependent presynaptic inhibition of receptor neurons. J Neurosci 28:6360-6371.

Plachez C, Puche AC (2012) Early specification of GAD67 subventricular derived olfactory interneurons. J Mol Histol 43:215-221.

Price JL, Powell TP (1970) The mitral and short axon cells of the olfactory bulb. J Cell Sci 7:631-651.

Shao Z, Puche AC, Shipley MT (2013) Intraglomerular inhibition maintains mitral cell response contrast across input frequencies. $J$ Neurophysiol 110:2185-2191.

Shao Z, Puche AC, Liu S, Shipley MT (2012) Intraglomerular inhibition shapes the strength and temporal structure of glomerular output. J Neurophysiol 108:782-793.

Shao Z, Puche AC, Kiyokage E, Szabo G, Shipley MT (2009) Two GABAergic intraglomerular circuits differentially regulate tonic and phasic presynaptic inhibition of olfactory nerve terminals. J Neurophysiol 101:1988-2001.

Shirley CH, Coddington EJ, Heyward PM (2010) All-or-none population bursts temporally constrain surround inhibition between mouse olfactory glomeruli. Brain Res Bull 81:406-415.

Toida K, Kosaka K, Heizmann CW, Kosaka T (1994) Synaptic contacts between mitral/tufted cells and GABAergic neurons containing calcium-binding protein parvalbumin in the rat olfactory bulb, with special reference to reciprocal synapses between them. Brain Res 650:347-352.

Toida K, Kosaka K, Heizmann CW, Kosaka T (1998) Chemically defined neuron groups and their subpopulations in the glomerular layer of the rat main olfactory bulb: III. Structural features of calbindin D28K-immunoreactive neurons. J Comp Neurol 392: 179-198. 
Toida K, Kosaka K, Aika Y, Kosaka T (2000) Chemically defined neuron groups and their subpopulations in the glomerular layer of the rat main olfactory bulb: IV. Intraglomerular synapses of tyrosine hydroxylase-immunoreactive neurons. Neuroscience 101:11-17.

Vaaga CE, Yorgason JT, Williams JT, Westbrook GL (2017) Presynaptic gain control by endogenous cotransmission of dopamine and GABA in the olfactory bulb. J Neurophysiol 117:1163-1170.

Vucini D, Cohen LB, Kosmidis EK (2006) Interglomerular centersurround inhibition shapes odorant-evoked input to the mouse olfactory bulb in vivo. J Neurophysiol 95:1881-1887.
Wachowiak M, Cohen LB (1999) Presynaptic inhibition of primary olfactory afferents mediated by different mechanisms in lobster and turtle. J Neurosci 19:8808-8817.

Wachowiak M, McGann JP, Heyward PM, Shao Z, Puche AC, Shipley MT (2005) Inhibition of olfactory receptor neuron input to olfactory bulb glomeruli mediated by suppression of presynaptic calcium influx. J Neurophysiol 94:2700-2712.

Whitesell JD, Sorensen KA, Jarvie BC, Hentges ST, Schoppa NE (2013) Interglomerular lateral inhibition targeted on external tufted cells in the olfactory bulb. J Neurosci 33:1552-1563. 